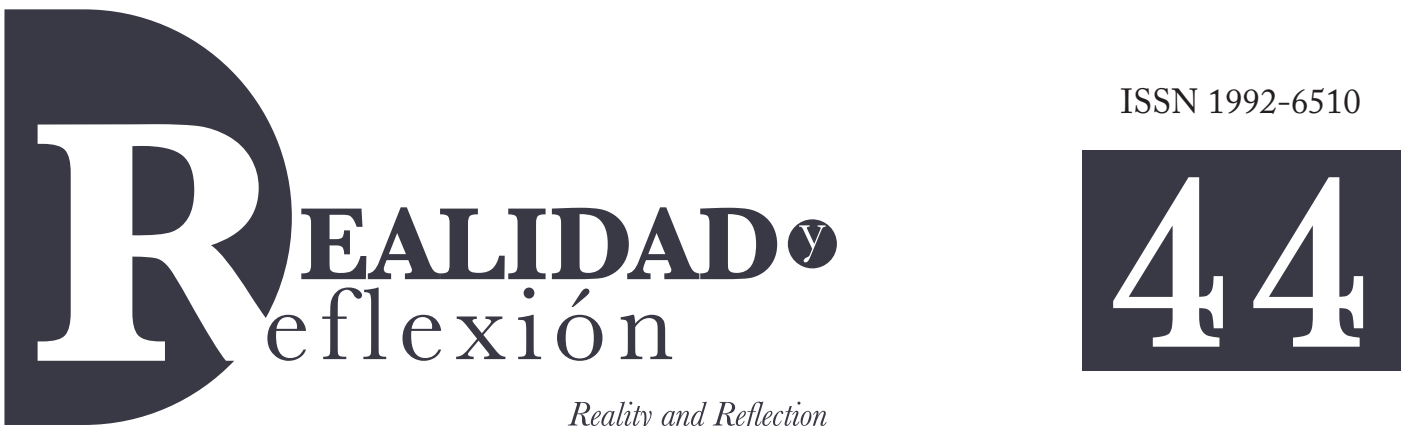

Reality and Reflection

Año 16, N 44, San Salvador, El Salvador, Centroamérica. Revista Semestral Julio-Diciembre 2016

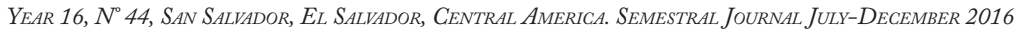

\title{
La niñez frente a su comunidad
}

\section{Children in front of their community}

\author{
Iván Gómez Trejos \\ Periodista, catedrático de la Universidad Francisco Gavidia \\ e investigador en temas de juventud y migración ICTI - UFG \\ igomez@ufg.edu.sv
}

\section{RESUMEN}

Una investigación que muestra la percepción de un grupo de niños y niñas de primaria sobre el entorno de su comunidad, plasmado en un dibujo. La expresión por excelencia de un niño es el dibujo. Una manifestación plasmada en el ser humano. El origen de todo, el hombre trazó lo que veía y sentía a través de su concepto más primitivo, pero más significativo. El Instituto de Ciencia, Tecnología e Innovación, ICTI, de la Universidad Francisco Gavidia vuelve a las bases para conocer la mente de un grupo de cincuenta niños, frente a su vivencia cotidiana. Su hogar y su entorno.

Palabras clave: niñez, comunidad, dibujo.

\section{ABSTRACT}

An investigation that shows the perception of a group of primary school children about the environment of their community, embodied in a drawing. The expression par excellence of a child is drawing. A manifestation embodied in the human being. The origin of everything, man drew what he saw and felt through his most primitive but more significant concept. The Institute of Science, Technology and Innovation, ICTI, of the University Francisco Gavidia returns to the bases to know the mind of a group of fifty children, in front of their daily experience. Your home and your environment.

Keywords: children, community, drawing. 


\section{Introducción}

En esta investigación participaron los estudiantes de quinto año de Licenciatura en Relaciones Públicas y Comunicaciones: Morena Guadalupe Parada, Gabriela Monchez y Ever Majano, quienes convivieron con los pequeños del Centro Escolar Los Alpes, ubicado en el municipio de Soyapango, en la zona central del departamento de San Salvador. La metodología utilizada fue la de lograr que los pequeños entre los 7 y 12 años dibujaran el entorno de su comunidad.

Las entrevistas grabadas posteriormente fueron entregadas para su análisis a tres psicólogos y un psiquiatra.

Los niños y su entorno de vida, ¿qué tanto saben? La percepción que tiene el infante sobre la realidad y el impacto que ésta tenga en él depende mucho de su edad. En los menores, en la etapa preescolar la realidad que tienen en su hogar y su comunidad inmediata, tiende a mezclarse con la fantasía, pues aún no existe para ellos una división muy clara entre estos dos entornos.

Pero esa mezcla fantasiosa puede dejar con la boca abierta a los padres de los escolares si conocieran el resultado de lo que piensan sus hijos sobre su hogar, sus vecinos o, incluso, el trabajo comunal que es responsabilidad de una municipalidad.

Así como un grupo de personas mayores llegan hasta tomar las calles y detener el tránsito en demanda de agua potable, con el objetivo de encontrar respuestas, así los niños demandan sus derechos. Y es el hecho de ser escuchados.
Los problemas de los niños no solamente están relacionados al cuido para evitar que caigan en las garras de las pandillas. Los niños también demandan muchas otras cosas más que complementan su infancia.

Los pequeños se preocupan por la limpieza, ríos, tránsito y hasta por espacios como barrancos, que podrían poner en riesgo sus vidas.

En este estudio participaron 53 niños y niñas de tercer y quinto grados, con el fin de conocer su percepción sobre su vida dentro de su comunidad. Con una hoja en blanco y un puñado de crayolas y lápices de colores, los niños captaron a la primera indicación lo que se buscaba. "Ah, mi casa donde yo vivo, mi comunidad. Claro, péreme". No, en realidad, la respuesta no fue así, pero a la mayoría sólo le faltó ese juego de palabras. Sorprendente.

Su maestro se retiró del aula para dejarlos solos, en libertad absoluta. Era el momento de castigar o premiar a lo que ellos calificarían como su casa y su entorno.

Entre risas fueron tomando en serio el objetivo de la visita.

No hubo quien quiso agregar a su compañero de clases, que también es su amigo y vecino. Felipe, "él pega”, “Trompeta”, "Chepe”, "Salva”, "Mosquito”, "Pelón”, "La Nena”, "La Princesa”, "La Pecosa" y otros no tan deseados de ser incluidos en este párrafo.

Es importante destacar el apoyo directo de los estudiantes de Licenciatura en Relaciones Públicas y Comunicaciones. Estos jóvenes fueron parte vital en la investigación. 


\section{La visita}

Una mañana cualquiera de un día de semana del calendario escolar. Al momento de la segunda hora de clases en el Centro Escolar Los Alpes, ubicado en una zona del casco urbano del municipio.

Un portón divide el final de un pasaje vehicular que facilita el mejor ambiente de estudios. El silencio.

Pero esos desniveles no son los que se escuchan ya a dentro de las instalaciones del recinto. Un grupo de niños ensayan el baile artístico que presentarán en las festividades patrias.

La energía de un grupo de niñas de tercer grado no es interrumpida ante la presencia de un pequeño grupo de estudiantes de la Universidad Francisco Gavidia. Ellas siguen bailando con sus azules faldas de uniforme, al ritmo del Torito Pinto.

Las risas nerviosas se trasladarán hasta el salón de clases de Tercero "A".

A la llegada a la puerta y antes que indique el profesor, un coro agudo de unas 30 voces saludan a los visitantes.

Caso seguido se les explicó que deberían hacer un dibujo que representara su casa y sus alrededores. Más claro que el dibujar el entorno donde viven. Lo esencial: su casa, sus vecinos, calles, en fin, todo lo representativo de sus vidas en la cotidianidad de su hogar.

Los varones fueron más activos. De inmediato comenzaron a recoger 2,3, y hasta 5 colores para pintar su entorno de vida. Tenían claro cuál era el objetivo: pintar cómo era donde vivían. Unos iban describiendo en voz alta lo que dibujaban: la tienda, la iglesia, la casa de su amigo, sus vecinos y el parque. Otros se dedicaban en plasmar en silencio detalles de su comunidad; un basurero, un río sucio, barrancos, policías y jóvenes pandilleros.

En el caso de las niñas, ellas estuvieron siempre más calladas. Dedicadas a plasmar con regla en mano, las mejores expresiones. Su concentración disciplinada estaba enfocada a presentar un buen trabajo: una hoja lo más limpia posible, sin manchones.

Los dibujos vienen siendo también la prueba de un trabajo comunal. La responsabilidad de la alcaldía estaría siendo medida por la inocencia de unos niños que no pasaban los 12 años. Sin campañas políticas que incidieran en la aprobación administrativa comunal.

\section{Los más chicos}

A unos 50 metros del salón de clases de los chicos de quinto grado, se ubica el Tercer Grado A. La inconformidad de un sector sindical de maestros que había llamado a una protesta de suspensión de clases, no impidió que la mayoría de los niños asistieran a la escuela del populoso municipio.

En contraste con la impaciencia del primer grupo, estos pequeños son más disciplinados. José hace limpieza pasando un trapo húmedo y curtido en el piso de ladrillo rojo que hace recordar las casas de los años sesenta, cuando las amas de casa buscaban cómo mantener bien brillante su sala.

A un solo tono de voz, los niños se ponen de pie y seguido, un sonoro saludo de buenos días. 
Pese a tener entre 8 y 9 años, este segundo grupo es mucho más callado y disciplinado que el de quinto grado.

En orden fueron tomando su página y colores. Casi en silencio iniciaron con la tarea de dibujar el lugar donde viven. Los pequeños finalizaron sus dibujos en un promedio de 25 minutos, contrario a sus compañeros, que casi ocupan la hora. La respuesta es fácil. Disciplina y orden de ideas.

Como parte del encuentro los jóvenes universitarios llevaron un refrigerio para convivir por una mañana con los pequeños.

\section{¿Cómo interpretar los dibujos de los niños?}

El dibujo es un canal de comunicación entre el niño o la niña y el mundo exterior. Según los psicólogos de la Unidad de Desarrollo Psicológico y Educativo, de San Salvador, por ética solo una persona especializada, como los psicólogos, puede interpretar los dibujos siguiendo protocolos establecidos para ese fin. $\mathrm{El}$ especialista debe tener en cuenta la condición biográfica y familiar de la persona que dibujó, así como su historia personal, que servirá de marco de referencia desde el cual está haciendo el dibujo.

Aparte de eso, es necesario tomar en cuenta que un dibujo es importante, pero no lo define todo. Es una expresión de sentimientos y deseos que pueden ayudar a saber, por ejemplo, cómo se siente el niño respecto a su familia, su escuela, etc. A través de los dibujos de los niños se pueden observar detalles que a una persona mayor le puede pasar inadvertidos. Así, el dibujo puede ser en la infancia, un canal de comunicación entre el niño y su mundo exterior, la primera puerta que el pequeño abra a su interior.

\section{Cinco pautas de interpretación del dibujo}

Existen algunas pistas que pueden orientar a los padres acerca de lo que dice el dibujo de su hijo. Sin embargo, no hay que olvidar que son pautas puramente orientativas. Según la especialista canadiense Nicole Bédard el dibujo dice muchas cosas, como por ejemplo:

\section{Posición del dibujo}

Todo lo que dibuja el niño en la parte superior del papel está relacionado con la cabeza, el intelecto, la imaginación, la curiosidad y el deseo de descubrir cosas nuevas. La parte inferior del papel nos informa sobre las necesidades físicas y materiales que pueda tener el niño. El lado izquierdo indica pensamientos que giran en torno al pasado, mientras el lado derecho, al futuro. Si el dibujo se sitúa en el centro del papel representa el momento actual.

\section{Dimensiones del dibujo}

Los dibujos con formas grandes muestran cierta seguridad, mientras los de formas pequeñas suelen estar hechos por niños que normalmente necesitan de poco espacio para expresarse; pero también pueden mostrar a un niño reflexivo o con falta de confianza.

\section{Trazos del dibujo}

Los continuos sin interrupciones suelen denotar un espíritu dócil, mientras el borrado o cortado puede revelar a un niño inseguro e impulsivo.

\section{La presión del manejo}

Una buena presión indica entusiasmo y voluntad. Cuanto más fuerte sea, más agresividad existirá, 
mientras más superficial sea demuestra falta de voluntad o fatiga física.

\section{Los colores del dibujo}

El rojo representa la vida, el ardor, el activo; el amarillo, curiosidad y alegría de vivir; el naranja, necesidad de contacto social y público e impaciencia; el azul, la paz y la tranquilidad; el verde, cierta madurez, sensibilidad e intuición; el negro representa el inconsciente; el marrón, la seguridad y la planificación. Es necesario añadir que el dibujo de un solo color puede denotar pereza o falta de motivación.

Esas pautas son simplemente unas pinceladas dentro del gran mundo que es el dibujo infantil. No debemos generalizarlas. Cada niño es un mundo, así como las reglas de interpretación del dibujo infantil.

\section{Trazos de su comunidad}

Detrás de la violencia cotidiana, en la que la mayoría de medios de comunicación han enfocado sus baterías cada día en El Salvador, a los autores de los dibujos parece no haberles afectado mucho.

Esconden una serie de sentimientos, que van más allá de las altas y bajas de la información sobre cifras oficiales de los asesinatos generados por la violencia social salvadoreña.

En estos niños, por hoy, su problema no es el que viven los adultos o lo mediático de las esferas gubernamentales, medios de comunicación o de la misma municipalidad. Existe en estos niños el reflejo de penas, alegrías críticas y esperanzas. Una necesidad de ser protegidos y una esperanza de paz.
No hay que olvidar que existe una Ley de Protección Integral de la Niñez y Adolescencia, LEPINA. Creada con base en el espirito formador de los infantes, desde la óptica del Estado. No se trata de hacer comparaciones con épocas pasadas sobre la responsabilidad en el derecho de corrección. Más bien, el de permitir más y mejores herramientas para una mejor formación del infante.

Esta es la parte que corresponde a la lectura psicológica que se le hiciera a 6 de los 50 dibujos realizados por los niños escolares.

\section{Análisis de los dibujos}

Dibujo n. 1 (árbol de casas)

Autor: Álvaro Edenilson G. A.; Tercer Grado A Edad: 9 años

Análisis: Dra. Carmen Mónchez, Médico Pediatra

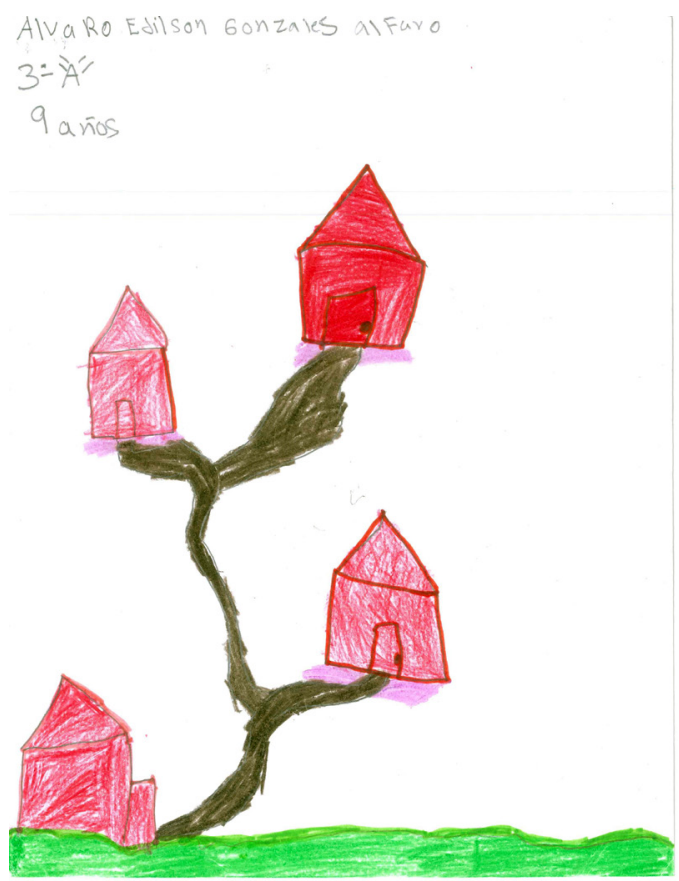




\section{Datos personales}

Le gusta dibujar, agradándole lo que dibujó. Al preguntarle por qué le gustó, la razón fue porque sus amigos y familiares viven cerca de su casa, pues lo que más le gustó del dibujo fueron las casas.

$\mathrm{Al}$ insistirle en que respondiera qué es lo que no le gustó del dibujo, destacó que todo le había parecido.

¿Pero, qué quiso dar a conocer Álvaro en su dibujo? Es un árbol genealógico, respondió. Los colores que escogió son sus favoritos.

¿Y si habría que agregarle algo, qué le agregaría? Columpios y amigos, dijo. Aseguró que no tendría nada que quitarle a su dibujo. Lo que más le gusta de su familia es que pasan juntos y visitan a su abuela.

Opinión de su maestra: es un niño muy extrovertido, responsable en sus estudios, con vocabulario aceptable a su edad.

\section{Observaciones:}

El niño Álvaro presenta en su aula habilidades cognoscitivas de acuerdo a su edad. Como todo niño, no deja de unirse a sus compañeros a algún desorden cuando el maestro no está en el aula. Sin embargo, cuando se le trata personalmente demuestra ser un jovencito sincero y seguro de lo que habla sobre el entorno en la comunidad donde vive.

Habla mucho de sus tías y primos. Posiblemente porque ellos viven cerca de su hogar. Muestra ser feliz en su casa y en la escuela, y pocas veces ha faltado a clases; y cuando no viene a clases, su madre lo acompaña para justificar su ausencia.
Da la impresión, que es ayudado en su casa para realizar sus tareas o reforzado en sus conocimientos por parte de personas mayores. Sus conversaciones son abiertas al comentar con una capacidad lingüística fluida. Se presenta como un niño muy extrovertido, con mucho arraigo a sus lazos familiares. Su capacidad para socializar con sus compañeros es notoria, ya que le gusta jugar al futbol y es líder en el campo de juego.

En relación con las actividades en el centro escolar, es colaborador cuando se le pide apoyar la limpieza o el ornato del centro educativo.

\section{Diagnóstico}

Se determina que el jovencito Álvaro Edenilson González Alfaro, de 9 años de edad, del Centro Escolar Los Alpes, no presenta dificultades a la hora de socializar, así como para desarrollarse dentro de un entorno estudiantil y familiar.

El muchacho presenta un esquema ejemplar en la educación familiar. El tema de valores humanos, como el respeto a las personas mayores, a sus maestros y compañeritos y vecinos es notorio en él.Esto determina que si se mantiene la educación en el hogar, cuando crezca no tendrá dificultades emocionales y afectivas, principalmente con el sexo femenino.

Demuestra valores morales muy bien infundados, lo cual se determina que se presenta como un niño con mentalidad y comportamiento acordes a su edad. La recomendación es que los padres se mantengan cerca de sus acciones, demostrando que se le ama; que él se sienta amado. 
Dibujo n. 2 (su casa, la de su abuela, árboles, la calle y su iglesia)

Autor: William Emanuel, Tercer Grado A

Edad: 9 años

Análisis: Dra. Carmen Móchez

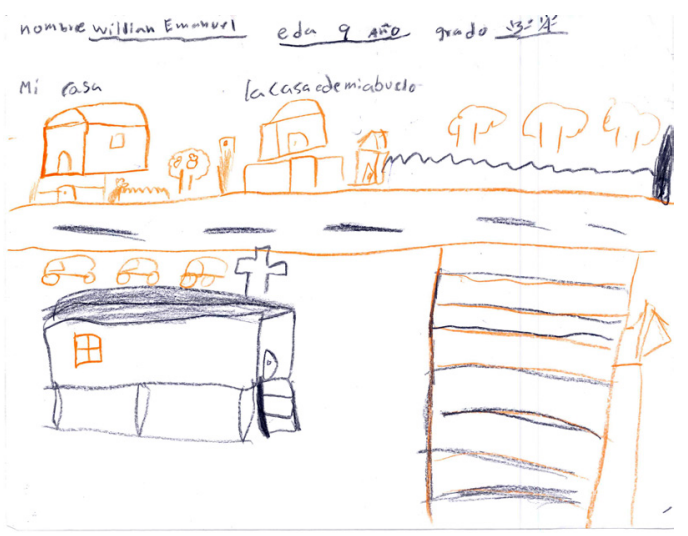

\section{Datos personales}

Le gusta dibujar y le agradan los árboles y la iglesia a la que va con su abuela, pasa mucho tiempo con ella. Lo que más le gustó de su dibujo fueron las casas. No fue claro en explicar lo que no le gustó dibujar, y es que no habría los colores favoritos como; café, verde, amarrillo y blanco.

Y ya finalizado el dibujo, William dice que él le quitaría la escalera. Cree que no se ve bien. Dice que lo que más le gusta de su familia es pasar con su abuelita.

Opinión de la maestra: un niño bastante tranquilo, aplicado y religioso, colaborador. Tiene una vida complicada porque su padre está preso. Confía bastante en su maestra. De momento se ha enfermado su abuelita, por lo que lo cuida su tía.

Al parecer ese acercamiento entre la familia ha evitado que el niño traslade sus emociones negativas de forma agresiva con sus compañeros.
La escuela en este caso ha tenido que ver mucho al prestársele atención a su caso familiar. El tema de su padre encarcelado, poco se comenta dentro de la escuela y se ha logrado que pase desinteresado por la curiosidad de sus compañeritos de saber qué ha ocurrido en su vida familiar.

En opinión de la maestra, los niños, ya, sea por los medios de comunicación o conversaciones en torno de sus comunidades, se enteran de casos en donde la autoridad detiene a personas, incluso han observado que dentro de algún juego infantil, ellos imitan a las personas cuando son registradas, incluso empujadas por la Policía.

\section{Observaciones}

Joven muy tímido. Le cuesta tener confianza en personas externas a su entorno; pues solo vive con su tía y abuela. No conoce de sus hermanos, y su madre se encuentra fuera del país y con un padre que guarda prisión. No obstante, está muy arraigado a su iglesia. No presenta a amigos de su edad, solamente amigos por parte del papá.

\section{Diagnóstico}

Se presenta como un niño muy tímido, con unas habilidades cognoscitivas no muy desarrolladas para su edad, presentando problemas al tener conversaciones con personas ajenas a su entorno social, así como a la hora de expresarse.

Por su situación familiar, se crea un concepto de familia un poco distorsionado para el niño. Aunque su mayor confianza radica en las personas mayores como su abuelita. Este comportamiento es positivo, ya que el jovencito adquiere verdaderos valores, los que difícilmente 
podría encontrar en otras personas fuera del hogar, aunque estas sean mayores.

Presenta problemas para socializar, así como para tener amigos acordes con su edad, obviamente se siente mejor con personas adultas, amigos de su padre. Esto puede provocar que en el futuro tenga problemas para poder unirse a grupos que estén acordes con su edad. Pero si se le da buena orientación, madurará acorde con sus responsabilidades, mostrándose seguro de sus decisiones.

Tiene algunas dificultades que por hoy no comprende en el entorno a los problemas familiares. Sin embargo, se observan valores morales muy profundos, siendo estos inculcados por el arraigo que presenta el plano religioso.

\section{Dibujo n. ${ }^{\circ} 3$}

Autora: Nohemy V. A., Tercer Grado A

Edad: 10 años

Análisis: Dra. Carmen Mónchez

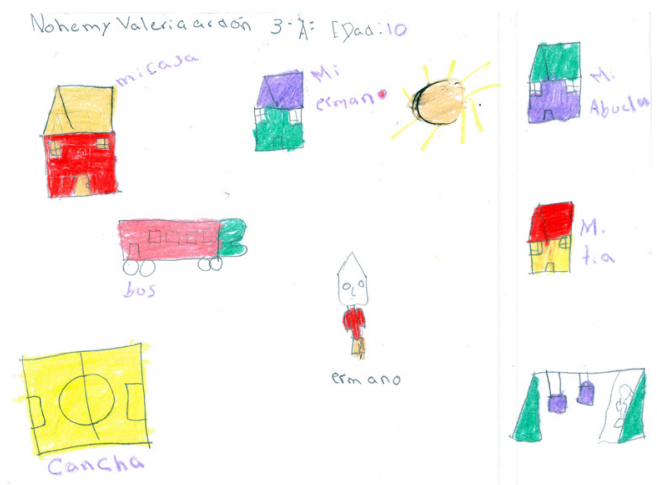

\section{Datos personales}

Le gusta el dibujo, principalmente dibujar casas, por la cercanía en que vive toda su familia. Y lo que más le agradó del dibujo fueron las casas y la cancha deportiva. Lo que no le gustó fue el autobús y el color negro.

Lo que expresó en su dibujo fue la unión familiar. Y los colores utilizados son con los que está pintada su casa.

Al preguntarle si le agregaría algo, Nohemy respondió que sus amigos más un hermano. $\mathrm{Y}$ desde luego, le quitaría el bus al dibujo. Dijo que se siente bien en su entorno familiar; sin embargo, al querer indagar qué es lo que más la hace sentirse bien en su hogar; su respuesta es generalizada con una tímida sonrisa, pues le gusta todo de sus familiares. Aparentemente no externa si tiene problemas afectivos en ese entorno o con sus vecinos.

Lo que piensa la maestra: niña bastante extrovertida. Es la mayor del salón de clases y actúa de manera muy coqueta. De alguna manera es influyente con el resto de sus compañeros. Presenta muchos problemas familiares. Rinde un promedio de 7 y tiene una personalidad fuerte. Algunas veces se le llama la atención cuando discute con sus compañeros. Demuestra pocas expresiones emocionales con las personas adultas.

Sin embargo, es preocupante que sus padres nunca han asistido a las reuniones en el complejo educativo. Se hace un trabajo desde la escuela, reforzando el amor, la solidaridad y el respeto. No obstante, el hogar es importante y poco se puede hacer desde la escuela si no existe el interés de sus padres.

\section{Observaciones en la entrevista}


Una niña bastante suelta a la hora de hablar, expresiones claramente notorias. Algunas respuestas no las respondía, lo hacía con gestos de no aceptación. Fue la única niña que se sentó con su pierna cruzada y miraba mucho su entorno. Sabe que su mamá trabaja por la noche; sin embargo, la pequeña dijo algo no muy claro: que su mamá trabajaba con hombres.

\section{Diagnóstico}

Se presenta como una niña muy extrovertida y poco controladora de su entorno social; observa una personalidad bastante fuerte y una mentalidad no muy acorde a su edad. Su concepto de familia se encuentra muy distorsionado, con un padre que no conoce y de una madre que se encuentra muy alejada.

En el entorno donde vive, al parecer es zona de tolerancia, donde trabaja su mamá. No es recomendable que una niña de diez años, esté viviendo en una zona de prostíbulos. Las autoridades deberían tomar en serio este caso, de manera que se busque alternativas de convivencia de esta menor, como el de mudarse a vivir con un familiar lejos de la zona.

Este tipo de vida le causa una mentalidad muy distorsionada de cómo debe de comportarse una mujer. La niña está indefensa, prácticamente sola, y en un tiempo cercano puede externar la necesidad de buscar ayuda.

No cuenta con los valores morales fundamentales que la familia le haya inculcado o una entidad como la iglesia. Por tanto, la niña presenta dificultades para unirse a grupos sociales de su edad, y en un futuro podría experimentar una frustración, así como también tendrá dificultades de formar grupo familiar.

Generalmente este comportamiento social se podría repetir cuando forme un hogar. Como también puede presentar dificultades en los estudios futuros o simplemente desinteresarse por la escuela, a la que hoy es su refugio.

Su adolescencia podría ser muy tormentosa porque de alguna manera podría ser excluida de las amistades de su infancia. Habría que preguntarse si la menor está integrada en algún programa por parte de la sociedad civil como Alcaldía, Iglesia u organizaciones que velan y trabajan por la sanidad mental de los niños.

Dibujo $n .^{\circ} 4$ (un espacio amplio, con un árbol central y a un extremo, un joven asesina a otro)

Autor: Edison Ernesto F. Quinto Grado A

Edad: 11 años

Análisis: Lcda.Julia Maritza Villalobos, psicóloga. Unidad de Género, Ministerio de Gobernación

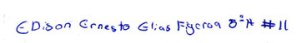

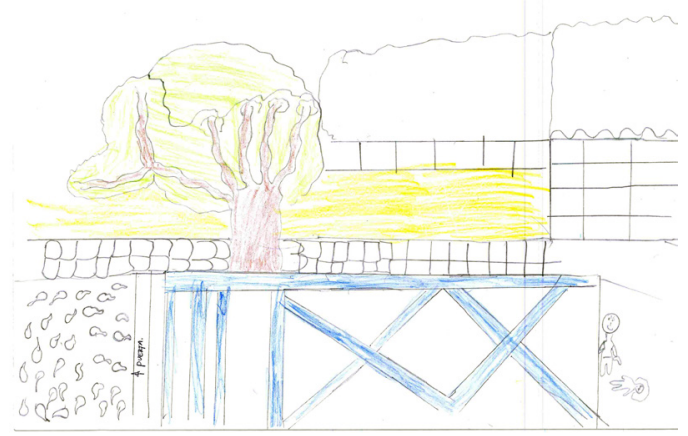




\section{Datos personales}

Mencionó su nombre completo, así como el de la colonia en donde vive. No tiene papá y en su casa viven, además de su madre, tía y primos. De alguna manera lo hace comportarse algunas veces como un niño tímido y callado. Es amante de los animes japoneses, entre ellos el Dragon Ball z. Además le gusta escuchar música electrónica y rap.

Como muchos niños de su edad, es amante del fútbol, aunque reconoce que el celular le provoca mucha distracción de sus responsabilidades.

Le gusta lo que dibujó, dijo que trató de copiar cómo es su casa. Y que los dibujos con pistola son porque al final de las casas donde vive llegan a matar a pandilleros y seguido se escuchan balazos. No logra decir con certeza qué es lo que más le gustó de su dibujo. Incluso no logra responder. Se nota muy tímido. Al final dice que le gustan los barrotes de la casa del vecino. Estos los coloreó de color celeste en el dibujo. Pero no sabe por qué le gustan.

Al buscar respuesta sobre lo que no le gustó de su dibujo, el niño vuelve a quedar callado. No le gustó la puerta que dibujó y que pertenece a su otro vecino; pero afirmó que había dibujado cómo es su colonia. Los colores no los eligió. Edison dibujó con sus propios colores.

Al preguntar sobre agregar algo al dibujo, dijo que le agregaría un cielo y más personas. Y para terminar, dijo que desearía quitar a los pandilleros de su dibujo. De su familia dijo que le gustan porque son alegres.

Opinión de su maestro: muy buenas relaciones sociales, tranquilo. Es muy juguetón. Sin embargo, platica algunas veces en clase, esto hace que se descuide en ocasiones con sus tareas. Aunque él argumenta que ayuda a su familia en la panadería.

\section{Diagnóstico psicológico}

El niño en su dibujo indica que tiene vecinos malos que lo atemorizan. La puerta de su vecino representa amenaza para él. Su coloreado demuestra inseguridad y confusión. El problema es que este niño no se siente identificado con su casa y su familia. Es bastante inseguro y representa violencia, aunque trata de ocultarlo. Quiere representar otra cosa, pero está muy descontento.

\section{Dibujo n. ${ }^{\circ} 5$}

Autor: Kevin H.1. Quinto grado A

Edad: 11 años

Análisis: Lcda.Julia Maritza Villalobos, psicóloga. Unidad de Género, Ministerio de Gobernación

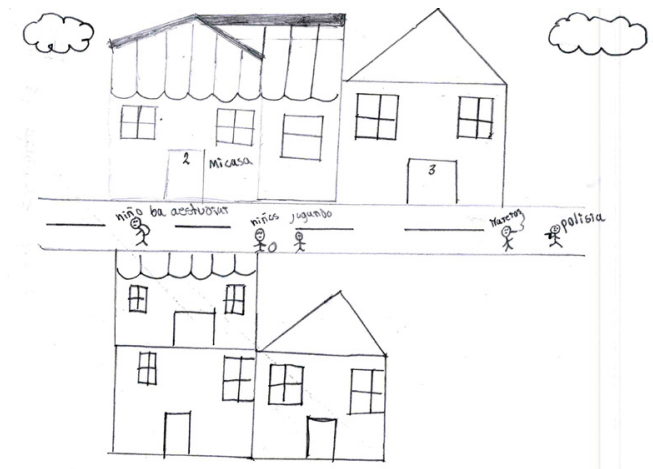

\section{Datos personales}

Es amante de los muñecos de la televisión. Muy comunicativo y dice que vive con sus padres $y$ se lleva muy bien con su hermano mayor de 16 años. Su pasatiempo es el fútbol, amante del 
Barcelona, mencionó como ejemplo a Messi. A nivel de música, le gusta bailar el reggaetón, dijo. A su corta edad ha logrado incorporarse a las responsabilidades que se le asignan.

De su dibujo lo que más le gustó fueron los niños jugando fútbol. Es realista. Dice que unos juegan en la calle y otros viven en esta, como es el caso de los pandilleros, a quienes ya está acostumbrado a ver. Sin embargo le tiene sin cuidado. A Kevin, le interesa más que los niños jueguen. Algo no acostumbrado de ver en las escuelas.

Kevin tiene los labios gruesos. Lo llaman con varios apodos: "Trompeta", "Trom" y hasta lo insólito que sin saber el significado lo llamen “Trompa de Falopio". Y él solo sonríe, pues en nada le afecta, porque al final de cuentas es popular tiene energías positivas, un carisma envidiable. Tanto así que conversó con los universitarios de manera suelta. Este niño es un líder.

Lo que quiso demostrar en su dibujo fue el peligro de violencia en las calles y cómo puede afectar a los niños. Y si tuviera que eliminar algo de su dibujo, desde luego es el lugar donde ubicó a los pandilleros.

Lo que dice su maestro: Kevin es muy bien portado, responsable. Tiene buenas relaciones con sus compañeros. Ayuda a su familia en el hogar y eso permite que sus familiares estén pendientes en que haga sus tareas.

\section{Análisis del psicólogo}

Kevin aparentemente es feliz con lo que tiene, quiso representar que es ordenado y disciplinado o simplemente que quiere ser así. Se enmarca en líneas rectas todo el dibujo. Siempre demuestra que hay una preocupación latente.

En su casa puede haber muchas exigencias, por las líneas remarcadas que trazó. $\mathrm{O}$ puede haber incluso violencia. Sin embargo, se adapta a la realidad y no tiene mucho contacto con los vecinos mayores.

\section{Dibujo n. ${ }^{\circ} 6$}

Autor: Kevin Josué M. Quinto grado A

Edad: 11 años

Análisis: Lcda.Julia Maritza Villalobos, psicóloga. Unidad de Género, Ministerio de Gobernación

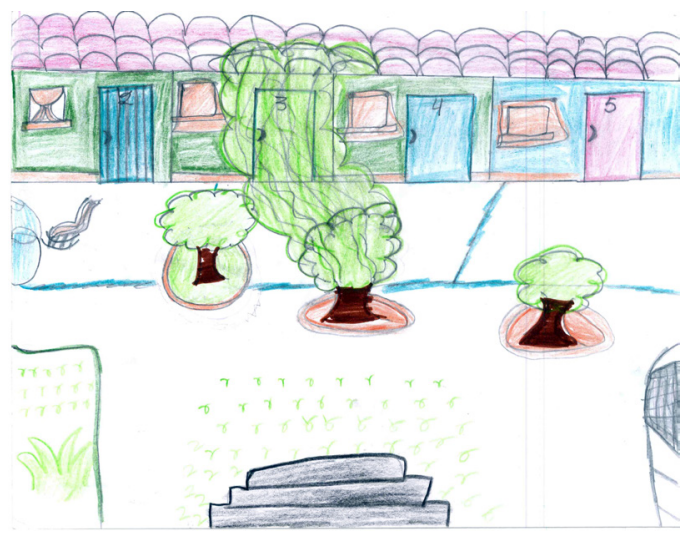

\section{Datos personales:}

Al consultarle sobre su nombre y dónde vive es exacto para dar referencia de cómo llegar a su casa. Vive cerca de la escuela, una colonia modesta de clase media. Es comunicativo, le gustan las caricaturas japonesas. A este niño le gusta todo tipo de música, incluso la que pudieron haber escuchado sus abuelos, por ejemplo la canción Hotel California que data de los años 70.

Este jovencito no solo pasa jugando en el celular. Afirma que tiene tiempo para hacer deporte como 
el fútbol, ya que es portero. Le gustó dibujar su casa, ya que tiene muchas plantas en su interior. Es observador del crecimiento de algunos árboles que han pasado el techo de la casa.

Lo que no le gusta es que la grama en invierno se enloda y se empolva en el verano. También se queja de la presencia de muchos zancudos, principalmente en el patio de la casa.

Coloreó con los matices de donde vive y si tendría que agregar más serían implementos deportivos como pelotas. $\mathrm{Y}$ al preguntarle si tuviera que quitarle algo al dibujo; piensa y luego responde que nada.

Le gusta mucho dibujar. De su familia lo que más le gusta es la atención, porque le ayudan hacer sus tareas.

Lo que dice su maestro: es callado, tiene muy buen comportamiento. Es respetuoso con sus compañeros y participativo en clase.

\section{Análisis psicológico:}

Kevin en sus dibujos presenta rasgos reprimidos de agresividad. Lo representa en los trazos de línea. Refleja baja autoestima e inseguridad porque no se dibuja él mismo. Al dibujar las puertas cerradas de su casa representa agresividad o violencia. Es reservado, se guarda consigo las cosas, expresa reserva personal. Oculta mucho. El árbol le puede traer recuerdos, pero no agradables, ya que lo dibujó más pronunciado. Por otra parte representa una familia cómoda, por las mesas que dibujó afuera. Lo positivo que pudo expresar al entrevistador, es más lo que él ha soñado, que sea su hogar.

\section{Conclusiones}

En el escritorio del investigador quedó una treintena de dibujos de los infantes escolares. Trazos tan significativos como la vida individual de los pequeños. Los dibujos no menos importantes que los expuestos en esta investigación, reflejan el eco que desde su psique expresa la niñez salvadoreña. La diferencia será su entorno: pobreza o bienestar, de eso dependerá con el cristal que lo estén percibiendo los niños.

Hay dibujos que reflejan los peligros de la comunidad; como un río contaminado, un barranco o simplemente el incumplimiento de la asistencia del tren de aseo. Es la intimidad, el silencio de estar concentrado en su pupitre, frente a un papel en blanco, con la libertad de expresar o contar cómo es la comunidad donde vive, cómo es su hogar, qué hay en el interior de este, cómo es la relación que existe con sus vecinos. Como adultos se podría decir que se trata de la buena convivencia o la tolerancia.

Los dibujos muestran lo que ven los pequeños más allá de un espacio llamado parque y en donde hay una aparente armonía durante los campeonatos deportivos. Lo que ven los pequeños detrás de esas actividades, que en ocasiones se convierten en celebraciones con alcohol y droga.

Este experimento con los niños permite examinar el hecho de cómo están viendo los menores a los adultos. Una alerta, también, a la comunidad docente, principalmente de educación primaria. De esta manera, y un tanto amena y divertida, a través de un dibujo hecho por ellos, estos pequeños, estos niños siempre dirán la verdad. En este caso, reflejada en una aparente hoja de papel bond. 